Avrupa Bilim ve Teknoloji Dergisi

Özel Sayı, S. 360-364, A ğustos 2020

(C) Telif hakkı EJOSAT'a aittir

Araștırma Makalesi
European Journal of Science and Technology

Special Issue, pp. 360-364, August 2020

Copyright (C) 2020 EJOSAT

$\underline{\text { Research Article }}$

\title{
Instagram Verileri ile Duygu Analizi
}

\author{
Pınar Kırc1 ${ }^{1 *}$, Elanur Gülbak ${ }^{2}$ \\ ${ }^{1}$ Bursa Uludağ Üniversitesi, Mühendislik Fakültesi, Bilgisayar Mühendisliği Bölümü, Bursa, Türkiye (ORCID: 0000-0000-0000-0000) \\ ${ }^{2}$ İstanbul Üniversitesi- Cerrahpaşa, Mühendislik Fakültesi, Bilgisayar Mühendisliği Bölümü, İstanbul, Türkiye (ORCID: 0000-0000-0000-0000)
}

(Bu yayın 26-27 Haziran 2020 tarihinde HORA-2020 kongresinde sözlü olarak sunulmuştur.)

(DOI: $10.31590 /$ ejosat.780129)

ATIF/REFERENCE: Kırc1, P. \& Gülbak, E. (2020). Instagram Verileri ile Duygu Analizi. European Journal of Science and Technology, (Special Issue), 360-364.

$\ddot{\mathrm{O} z}$

Bu çalışmada emoji sınıflandırılması sonucunda iki adet akıllı telefon markasının karşıılaştırılması yapılmıştır. Çalışmanın birinci kısmında Selenium sayesinde ilgili instagram sayfalarına ulaşılarak ilk gönderilerin yorumları uygulamaya çekilmiştir. Bu kısımda ek kütüphane kullanmadan, kullanıcı girişi yapmadan verilerin çekilmesi hedeflenmektedir. Bu amaçla sayfanın yüklenmesini bekleyen uygun bekleme süreleri eklenmiş̧ir. Çalışmanın ikinci kısmında ise çekilen emojiler başlangıçta ayarlandı̆̆ı üzere pozitif, negatif ve nötr olarak sınıflandırılmış ve sonuç pasta grafiğinde oranlara dökülmüştür.

Anahtar Kelimeler: Instagram, Duygu analizi, Veri.

\section{Sentiment Analysis with Instagram Data}

\begin{abstract}
In this study, as a result of emoji classification, comparison of two smart phone brands was made. In the first part of the study, thanks to Selenium, the relevant instagram pages were reached and the comments of the first posts were put into practice. In this section, it is aimed to extract data without using additional libraries and user logins. For this purpose, proper waiting times are added for loading the page. In the second part of the study, the collected emojis were classified as positive, negative and neutral, and the results were presented in a pie chart.
\end{abstract}

Keywords: Instagram, Emotion analysis, Data.

\section{Giriş}

Hem ürünleri hem de markayı bir adım ileriye götürebilmek için müşterilerin siz ve ürünler hakkında ne düşündüğünü bilmek oldukça önemlidir. Bu sayede ürünleri geliştirebilir veya müşterilerin beklentileri daha iyi anlaşılabilir. Instagram gönderileri ile müşterilerden iş veya çalışmalar ile ilgili görüşleri kolayca alınabilir.

Instagram 5 Ekim 2010 tarihinde IOS için ücretsiz bir uygulama olarak Kevin Systrom ve Mike Krieger tarafindan kurulmuştur. Uygulamanın bu kadar sevilmesinin ilk nedeni, içerisinde bulundurduğu 11 fotoğraf filtresiyle çekilen fotoğrafları daha güzel hale getirmesidir. Buna ek olarak kullanıcılar Instagram'da paylaştıkları fotoğrafları diğer sosyal ağlarda da (Facebook, Twitter, Flickr ve Tumblr) anlık, pratik ve hızlı bir şekilde paylaşma imkanına sahiptir. Tüm bunlar uygulamayı kısa sürede popüler yapmıştır. Kısa zamanda geniş kitleler tarafından kullanılan ve önerilen Instagram, çok geçmeden 1 milyon kullanıcı barajına ulaşmıştır.

\footnotetext{
* Pınar KIRCI: Bursa Uludağ Üniversitesi, Mühendislik Fakültesi, Bilgisayar Mühendisliği Bölümü, İstanbul, Türkiye, ORCID: 0000-0000-00000000, pinarkirci@uludag.edu.tr
} 
Instagram, Ocak 2011'de TechCrunch tarafindan verilen "En iyi mobil uygulama" kategorisinde ödül kazanarak bir nevi kendini kanıtlamıştır. Aynı tarihlerde Instagram, etiket (\#) sistemini duyurmuştur. Böylelikle kullanıcılar sadece arkadaşlarıyla değil aynı etiketi kullanarak paylaşım yapan tüm kullanıcılarla etkileşime geçebilmiştir. 2011 Instagram için verimli bir yıl olmuştur zira yıl bitmeden Instagram yaptığı resmî bir açıklamayla, 15 milyon üyeye ve 400 milyon fotoğraf paylaşımına ulaştığını duyurmuştur [1].

1990'larda internet ve e-mail kullanımı Japonya'da yaygınlaşmaya başlamıştı ancak Shigetaka Kurita iletişimde büyük değişimler getiren ve iletişim aktörlerini değiştiren e-posta ve internet iletişimiyle ilgili bir sorun fark etti. Geleneksel Japon yazılı iletişiminde emaillerin yerine kullanılan mektuplara bakıldığında uzun ve soyut anlatımlar büyük yer kaplıyordu. Japonlar için duygularını karşıya anlatmak, soyut durumları uzun uzun betimlemek geleneksel Japon mektuplaşmasının temellerini oluşturuyordu. İnternet üzerinde iletişim, ülkede yaygınlaştıkça uzun uzun insanların duygu ve soyut durumları anlattı̆̆ mektuplar, yerini kısa ve özet olarak değerlendirilebilecek e-postalara bırakmıştı. Kısa ve duyguların anlatılamadığı e-postalar Japonlar üzerinde negatif etki bırakıyordu.

Bu duruma çözüm bulmak isteyen Kurita, sokak işaretleri, Çince karakterler ve manga çizgi romanlarında kullanılan sembollerden yola çıkarak, duyguları ve diğer soyut fikirleri temsil eden bir dizi sembol geliştirdi. Emojilerin babası olarak bilinen Kurita, bulduğu sembollerin tüm dünyada kullanılacağını tahmin edemezdi. Bu günlerde Amerikan iletişim kültürünün bir parçası olarak görülen emojiler aslında Apple'ın 2011'de yaptığı güncelleme sonrası küresel iletişimde yerini almaya başladı [2-3].

\section{Duygu Analizi Nedir?}

Duygusal analiz veya fikir madenciliği, doğal dil işleme alanında, insanların metindeki öznelliğin hesaplı muamelesi yoluyla düşüncelerini, duygularını, değerlendirmelerini, tutumlarını ve duygularını analiz eden aktif bir çalışma alanıdır [4].

Duygu analizi, basit bir şekilde, bir metin parçasının pozitif, negatif veya nötr olup olmadığı üzerine (istatistiksel olarak) çalışma sürecidir. Duyarlılık analiz yaklaşımlarının çoğu iki formdan birini alır: kutupluluk temelli, metin parçalarının olumlu veya olumsuz olarak sınıflandırıldığı veya değerlilik yoğunluğunun göz önüne alındığı değerlik temelli olarak sınıflandırıldığı. Örneğin, "iyi”" ve "mükemmel" kelimeleri kutupsallığa dayalı bir yaklaşımda aynı şekilde ele alınacak; "mükemmel" ise değerlik temelli bir yaklaşımda "iyi" den daha olumlu olarak değerlendirilecektir [5-6].

Günümüzde işletmeler, büyük ölçüde verilere bağımlıdır. Bununla birlikte, bu verilerin çoğu, e-postalar, sohbetler, sosyal medya, anketler, makaleler ve belgeler gibi kaynaklardan gelen yapılandırılmamış metindir. Twitter ve Facebook'tan gelen mikro blog içeriği, yalnızca içerdiği veri miktarı nedeniyle değil, aynı zamanda duyguları ifade etmek için kullanılan dil türünden, yani kısa formlardan, emojilerden ve ifadelerden dolayı da incelemede ciddi zorluklar içermektedir [4].

\section{Proje Tasarımı}

Hem ürünleri hem de markayı bir adım ileriye götürebilmek için müşterilerin siz ve ürünler hakkında ne düşündüğünü bilmek oldukça önemlidir. Bu sayede ürünleri geliştirebilir veya müşterilerin beklentileri daha iyi anlaşılabilir. Instagram gönderileri ile müşterilerden iş veya çalışmalar ile ilgili görüşleri kolayca alınabilir.

VADER, Valence Aware Dictionary and SEntiment Reasoner anlamına gelir. Lexicon ve kurallara dayalı bir duyarlılık analiz kütüphanesidir. Kütüphane, Sentiment Analytics alanında popülerdir [7]. VADER basit bir kural tabanlı duyarll1ık analizörüdür. Sözcüksel özellikler listesi ve bunlarla ilgili duyarlılık ölçütlerinden oluşur. Dilin gramer ve sözdizimsel kullanımına dayanarak, metnin duyarlılığını belirlemek için kullanılan birkaç kural oluşturulmuştur. Sözlük, temel olarak, her bir kelimeye pozitif değer veya negatif değer olarak semantik yönelimli değerler atanan kelimelerin bir listesidir .VADER sözlük listesinde, özelliklere -4 ila +4 arasında değerler atanır, burada -4 aşırı negatif ve +4 aşırı pozitifdir [8-9]. VADER, cümlelerdeki emojiler, slanjlar ve kısaltmalar ile çok iyi bir performans sergilemektedir [4].

İlk kısımda Selenium ile Instagram üzerinde Marka-1 ve Marka-2 instagram hesaplarından yorum çekme işlemi gerçekleştirildi. Selenium'u tanımlayacak olursak tarayıcı otomasyon aracı diyebiliriz. Yani web sitesi üzerindeki bazı adımları, belirleyeceğimiz şekilde tarayıcı üzerinde otomatik test eden bir araç. 


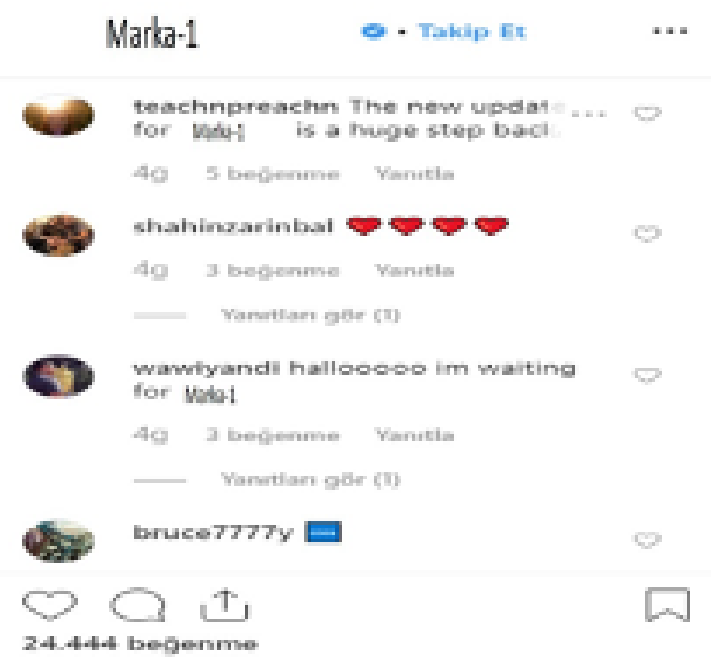

Şekil 1: 'Marka-1', 14.06.2019 tarihli gönderisindeki yorumlar.

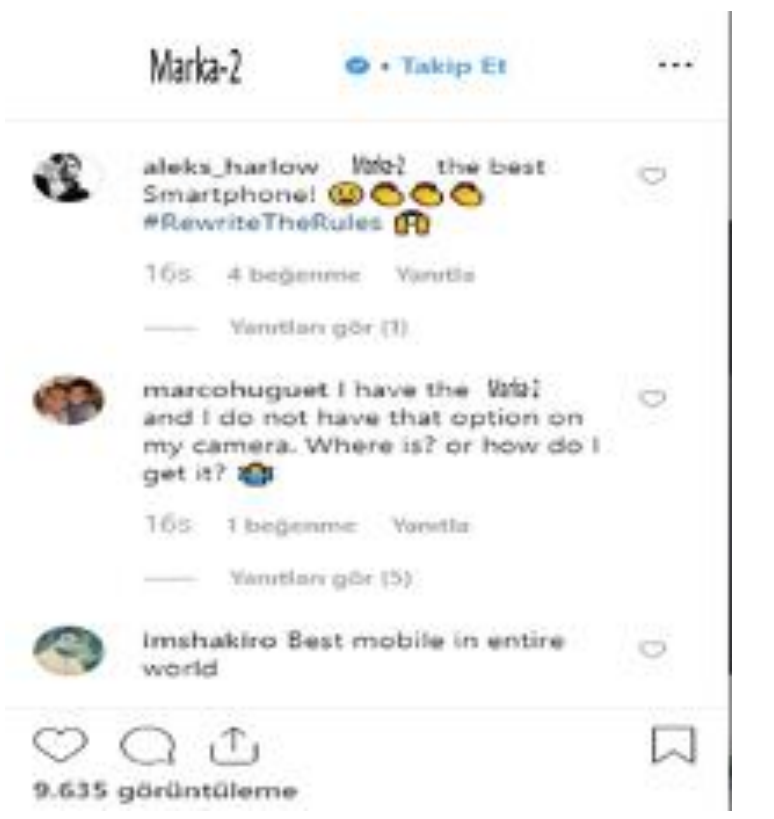

Şekil 2: 'Marka-2', 17.06.2019 tarihli gönderisindeki yorumlar.

\section{Sonuçlar}

Kullanılacak kütüphanelerin daha önce nerelerde kullanıldığı araştırıldı ve bu kütüphaneler (Selenium, Emoji ,Time, Pyplot) kuruldu. İki fonksiyon tanımlandı. İlk fonksiyon instagram hesabındaki fotoğrafın alınacağı kullanıcı adı ve hangi postu kullanacaksa onu parametre olarak almaktadır. Bu sayede, ilk fotoğrafın linki ile gönderi, otomatik olarak ana sayfaya gelmektedir. Burada bulunan her bir yorum kelimesi stringe aktarılmaktadır. Bu yorumlar fonksiyonun çağrılması ile birlikte notebookta belirmektedir.

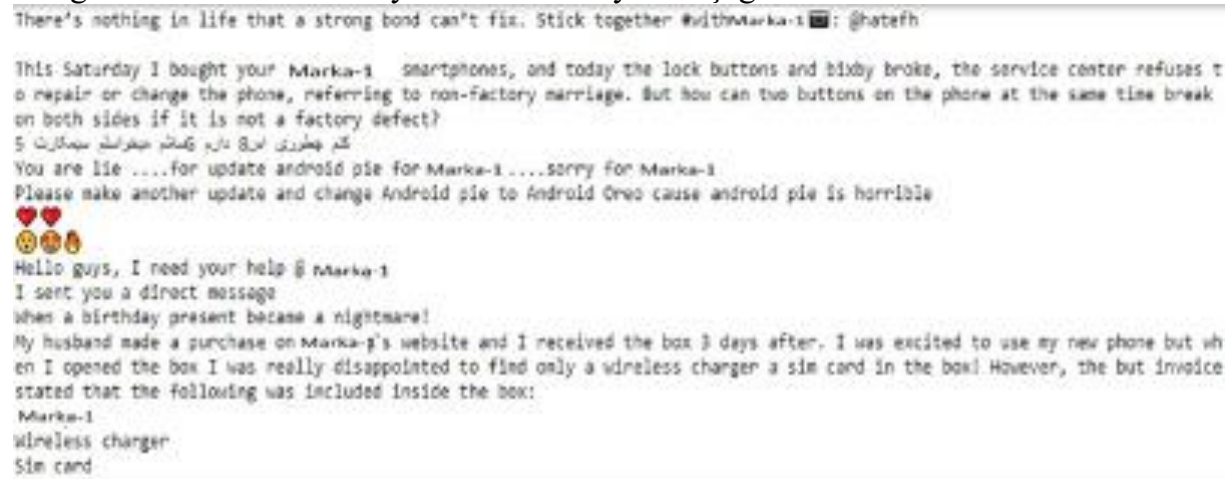

Şekil 3: 14.06.2019 tarihli 'Marka-1'gönderisindeki yorumlar. 


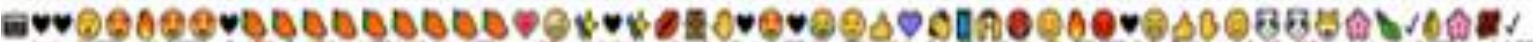

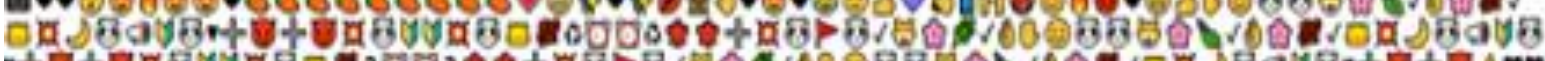

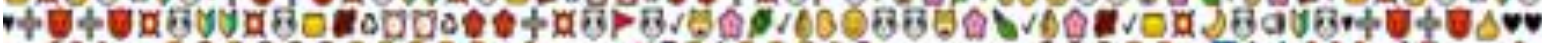

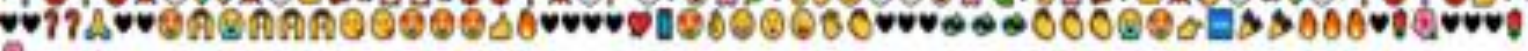 (6)}

Şekil 4: 14.06.2019 tarihli 'Marka-1' gönderisindeki yorumlardaki emojiler.

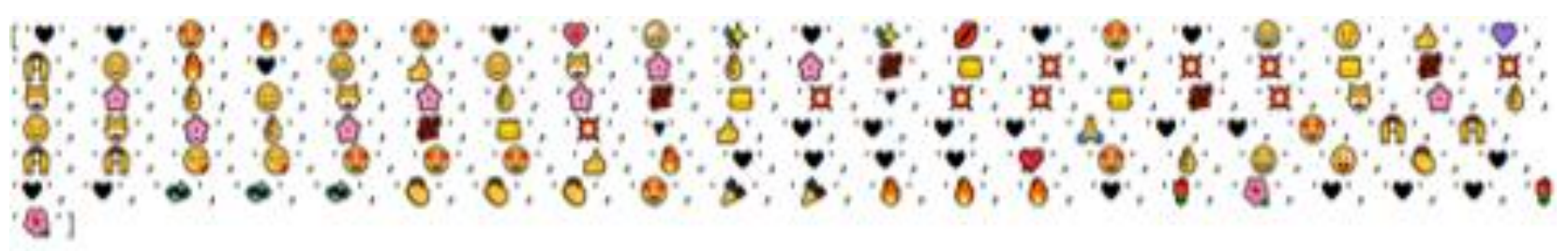

Şekil 5: Pozitif Emojiler.

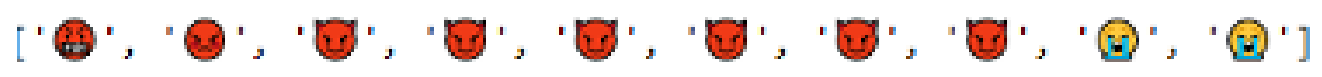

Şekil 6: Negatif Emojiler.

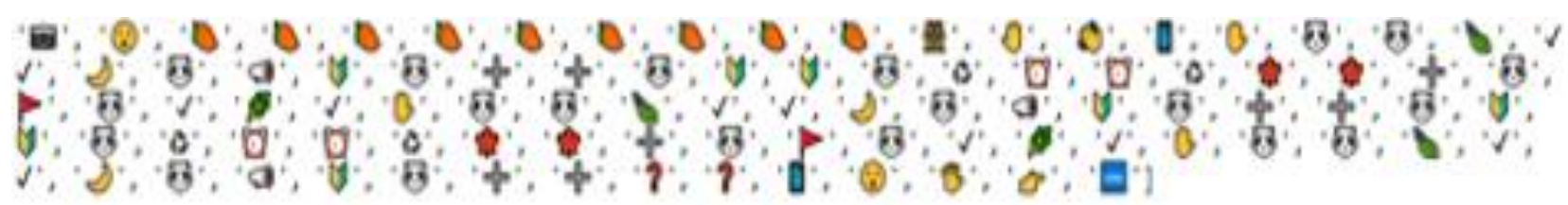

Şekil 7: Nötr Emojiler

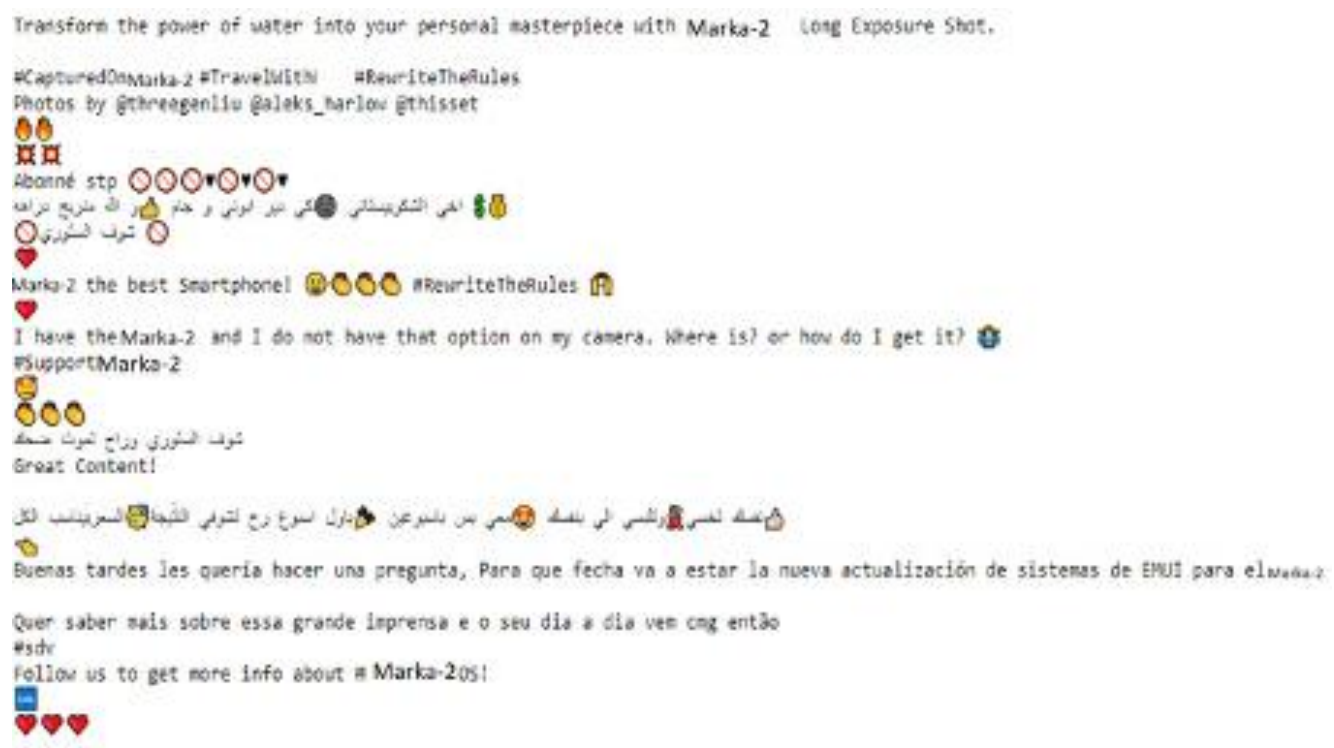

Şekil 8: 17.06.2019 tarihli 'Marka-2'gönderisindeki yorumların bir kısmı.

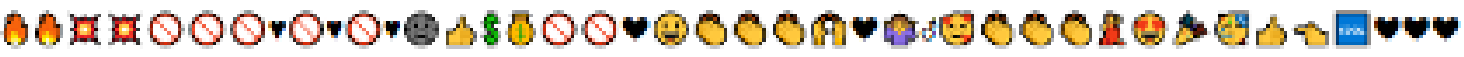

Şekil 9: 17.06.2019 tarihli 'Marka-2' gönderisindeki yorumlarda yer alan emojiler. 


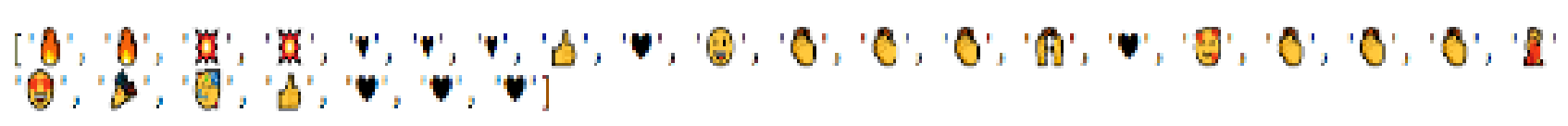

Şekil 10: Pozitif Emojiler.
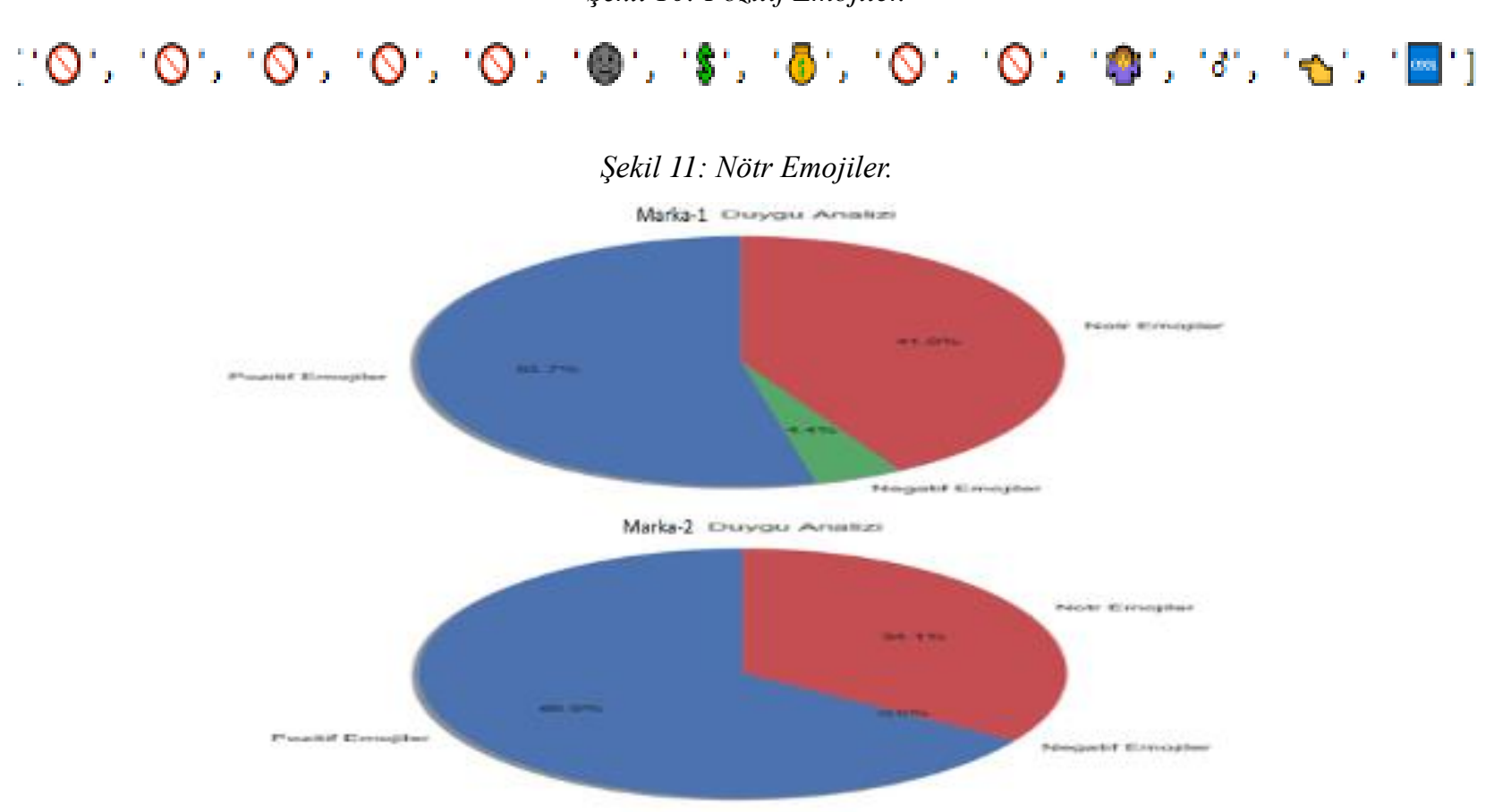

Şekil 12: Marka-1 ve Marka-2 son instagram gönderilerinin karşılaştırmalı grafiği

\section{Sonuç}

Şimdilerde, kurum kimliğini tanıtan hikayeler, görsellerle eğlenceli ve etkili bir şekilde anlatılabilmekedir. Web sitesine yönlendiren, personelin müşterilerine nasıl bir hizmet verdiği hakkında bilgi veren görseller kullanılabilir. Bu nedenle günümüzde, Instagram hesabında paylaşılan görsellerin ve mesajların, marka kimliğini ve kurum kültürünü stratejik ve en doğru şekilde temsil etmesi, dikkat edilmesi gereken en önemli nokta olmaktadır.

Bu proje ile gönderilere verilen tepkinin nasıl ve ne oranda olduğu ölçülmektedir. Çalışmada, Python kullanılmıştır. Python'ın tercih edilmesinin sebebi, öğrenme isteği ve nesne yönelimli olmasıdır. Bu çalışmanın sonucunda Selenium kullanılarak elde edilen instagram verileri ile ilgili instagram hesabının son gönderisindeki yorumlardaki emoji analizleri yapılmış, şekillerdeki veriler elde edilmiştir. Elde edilen sonuçlarla markalar diğer markalarla olan kıyaslamalarını yapabilir ve kendilerine, aldıkları geri bildirimler sayesinde, en uygun yolu kolayca çizebilirler.

\section{Kaynakça}

[1] Koçoğlu, S. (2018). Instagram Tarihi: Instagram Nedir? Nasıl Kullanılır? Ne İşe Yarar.

[2] Şen E. (2017). Emojilerin Şaşırtan Hikayesi ve Teknik İşleyişi. https://emoji.com.tr/emojilerin-sasirtan-hikayesi/

[3] Hutto, C. J., \& Gilbert, E. (2014, May). Vader: A parsimonious rule-based model for sentiment analysis of social media text. In Eighth international AAAI conference on weblogs and social media.

[4] Pandey, P. (2018). Simplifying Sentiment Analysis using VADER in Python (on Social Media Text).

https://medium.com/analytics-vidhya/simplifying-social-media-sentiment-analysis-using-vader-in-python-f9e6ec6fc52f

[5] Araque, O., Zhu, G., \& Iglesias, C. A. (2019). A semantic similarity-based perspective of affect lexicons for sentiment analysis. Knowledge-Based Systems, 165, 346-359.

[6] http://t-redactyl.io/blog/2017/04/using-vader-to-handle-sentiment-analysis-with-social-media-text.html

[7] Rahul Vaish,2018, VADER and Sentiment Analysis-Python

https://medium.com/@rahulvaish/vader-and-sentiment-analysis-python-eae70ecef454

[8] Urologin, S. (2018). Sentiment Analysis, Visualization and Classification of Summarized News Articles: A Novel Approach. International Journal of Advanced Computer Science and Applications, 9(8).

[9] Poecze, F., Ebster, C., \& Strauss, C. (2018). Social media metrics and sentiment analysis to evaluate the effectiveness of social media posts. Procedia computer science, 130, 660-666. 